\title{
Diversity and Inclusion: Key to Improve Productivity - A Case Study on WIPRO
}

\author{
Krithi ${ }^{1}$ \& Ramesh Pai $^{2}$ \\ ${ }^{1}$ Research Scholar, College of Management \& Commerce, Srinivas University, Mangalore, \\ India \\ ${ }^{2}$ Research Professor, College of Management \& Commerce, Srinivas University, Mangalore, \\ India \\ E-Mail: krithiks2020@gmail.Com
}

Area of the Paper: Business Management.

Type of the Paper: Research Case Study.

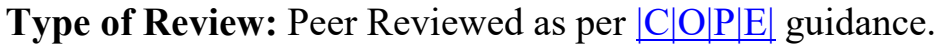

Indexed In: OpenAIRE.

DOI: http://doi.org/10.5281/zenodo.3977553.

Google Scholar Citation: IJCSBE.

\section{How to Cite this Paper:}

Krithi, \& Pai, Ramesh. (2020). Diversity and Inclusion: Key to Improve Productivity - A Case

Study on WIPRO. International Journal of Case Studies in Business, IT, and Education (IJCSBE), 4(2), 18-27. DOI: http://doi.org/10.5281/zenodo.3977553.

International Journal of Case Studies in Business, IT and Education (IJCSBE)

A Refereed International Journal of Srinivas University, India.

(C) With Authors.

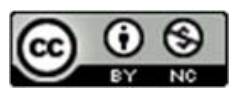

This work is licensed under a Creative Commons Attribution Non-Commercial 4.0 International License subject to proper citation to the publication source of the work.

Disclaimer: The scholarly papers as reviewed and published by the Srinivas Publications (S.P.), India are the views and opinions of their respective authors and are not the views or opinions of the S.P. The S.P. disclaims of any harm or loss caused due to the published content to any party. 


\title{
Diversity and Inclusion: Key to Improve Productivity - A Case Study on WIPRO
}

\author{
Krithi $^{1}$ \& Ramesh Pai ${ }^{2}$ \\ ${ }^{1}$ Research Scholar, College of Management \& Commerce, Srinivas University, Mangalore, \\ India \\ ${ }^{2}$ Research Professor, College of Management \& Commerce, Srinivas University, Mangalore, \\ India \\ E-Mail: krithiks2020@gmail.Com
}

\begin{abstract}
Diversity is an essential consideration which all employees have to deal with throughout their careers at one stage today. Diversity of the workforce means differences and similarities between people working in an organization. This diversity can be in terms of age, ethnicity, types of cognition, employment, appearance, education, ethnic groups, family background, social status, community, and more. Therefore, people who work in an organization with different demographic backgrounds make a diverse workforce. Diversity and inclusion are the mission, policies, and procedures of an organization to facilitate a diverse workforce and leverage the benefits of diversity to achieve a competitive business advantage. The notion of diversity and inclusion of the workforce gained tremendous popularity with globalization and the need for companies to expand their business internationally to reach consumers worldwide. A diverse workforce is reflecting a changing world and market place. A diverse work environment is the utmost priority at Wipro. Diversity and inclusion play a vital role in organizational sustainability. This study focuses on the analysis of diversity and inclusion practices followed by Wipro to improve productivity.
\end{abstract}

Keywords: Workforce diversity and Inclusion, Wipro Ltd best practices, D\&I Sustainability reports, measures to manage diversity, and ABCD Analysis.

\section{INTRODUCTION :}

Advances in Technology and Communications are resulting in the emergence of a new world economy which is bringing the population of the world closer than ever before. The dawn of this phenomenon has necessitated the corporate world, educational systems, and other institutions to explore novel ways to hire their employees. Recruitment, training, and retention of the best talent have become an urgent need for institutions and corporations. The concepts of Diversity Inclusion and Diversity Management are now strategic concerns for multinationals worldwide [1]. Diversity refers to a mosaic of people who bring a variety of backgrounds, perspectives, values, and benefits as assets to the groups and organizations with which they interact [2]. Inclusion emphasizes encouraging engagement, embracing diversity, and incorporating it into day to day work. It's all about valuing differences and respectfully embracing the individuality between individuals; building a workplace where an employee is accepted, and being viewed as an insider by those in a team. People feel accepted, valued, committed, appreciated, and inspired in an inclusive organization: there is an overall sense of belonging. Diversity and inclusion are strong forces together [3]. India has a high level of diversity in its workforce, especially in global firms. Managing diversity in the workplace is a key challenge in the globalized world today [4]. People with different cultural backgrounds behave differently even at the workplace. Workplaces in MNCs today are highly diversified with the employees of different states, different countries, different age groups, cultures, religions, races, ethnicities, groups, color, and gender. People from various places and societies bring varied culture to the workplace in addition to the best talent. Managing cultural diversity, racial, and differences in sex can be very challenging for an organization in the present scenario given the multi-cultural dimensions that exist among groups in organizations. 
The very vision of the company is to create an inclusive workplace and leverage diversity for a sustainable competitive advantage [5]. Through globalization, more contact between people from different cultures, ideologies, and backgrounds is expected than ever before. People are no longer living and working in an insular marketplace; now they are part of a global economy with competition coming from almost every continent. Of this reason, companies and non-profits need diversity to become more innovative and open to change. Maximizing and capitalizing on diversity in the workforce has become a major concern for management today [6]. The diversity can be classified into three dimensions (1) primary dimension, (2) secondary dimension, (3) the Territory dimension.

Table 1: Dimensions of diversity [7]

\begin{tabular}{|l|l|l|}
\hline Dimensions & Attributes \\
\hline Primary & $>$ Race \\
& $>$ Ethnicity \\
& $>$ Agender \\
\hline secondary & $>$ Disability \\
& $>$ Religion \\
& $>$ Sexual orientation \\
& $>$ Geographic origin \\
& $>$ Family status \\
& $>$ Economic status \\
& $>$ Political orientation \\
& $>$ Work experience \\
& $>$ Education \\
& $>$ Nanguage \\
& $>$ Beliefs \\
& $>$ Assumptions \\
& $>$ Perceptions \\
& $>$ Attitudes \\
& $>$ Feelings \\
& $>$ Galues \\
& $>$
\end{tabular}

Source: table1 [7]

\section{RELATED WORK :}

Some of the scholarly papers on diversity and inclusion of the workplace are shown in fig along with the input and reference.

Table 2: Related publication on workforce diversity and inclusion by different authors

\begin{tabular}{|l|l|l|}
\hline $\begin{array}{l}\text { S. } \\
\text { No }\end{array}$ & Contribution & Reference \\
\hline 1. & $\begin{array}{l}\text { Management of diversity ensures that all employees can } \\
\text { enhance their abilities and enhance their self-development } \\
\text { and there contribute to the organization }\end{array}$ & Deshpande, A. (2014) [8] \\
\hline 2. & $\begin{array}{l}\text { A holistic view of human resources strategies and policies that } \\
\text { adopt the work-life needs of women's diverse workforce in } \\
\text { the current business world. }\end{array}$ & Singh, S., et al. (2017) [9] \\
\hline 3. & $\begin{array}{l}\text { Companies understand the importance of diversity and } \\
\text { inclusion at their places of employment and Upgrades Scores } \\
\text { of engagement ensure growth at member, group, and } \\
\text { organizational level Strong results. }\end{array}$ & Itam, U., et al. (2019) [7] \\
\hline
\end{tabular}

Krithi et al, (2020); www.srinivaspublication.com 


\begin{tabular}{|l|l|l|}
\hline 4. & $\begin{array}{l}\text { The formulation of the workforce for a beneficial outcome } \\
\text { such as imagination, problem-solving and innovation, and } \\
\text { also Diversity can lead to other negatives, such as conflicts, } \\
\text { diminishing groups Quality and decreased group cohesion }\end{array}$ & $\begin{array}{l}\text { Roberge, M. É., et al. } \\
(2010)[10]\end{array}$ \\
\hline 5. & $\begin{array}{l}\text { A diversified workforce it's the very essence of today's } \\
\text { scenario, but it's a huge challenge to handle such a diverse } \\
\text { workforce Administration. Hiring a diversified workforce } \\
\text { will lead to improved productivity, }\end{array}$ & $\begin{array}{l}\text { Solanki, R. B., et al. } \\
\text { (2016) [11] }\end{array}$ \\
\hline
\end{tabular}

\section{OBJECTIVES OF THE STUDY :}

1. To study the diversity and inclusion concepts.

2. To know the various dimensions of diversity and practices followed by Wipro Ltd.

3. To understand strategies to improve diversity and inclusion in the workplace.

4. To analyze diversity and inclusion using the $\mathrm{ABCD}$ analysis framework.

\section{RESEARCH METHODOLOGY :}

Based on the secondary data this case study is developed and published sources are taken into account for data collection. This article describes how through diversity and inclusion measures Wipro co ltd has attempted organizational sustainability. Using the information collected from journal articles, newspaper, and business websites including the website of Wipro company detailed evaluation are presented.

\section{OVERVIEW OF WIPRO :}

Wipro is a dominant global IT, consulting, and business process Services Company. The company tacks the power of cognitive computing, hyper-automation, robotics, cloud, analytics, and emerging technologies to benefit customers adapt to and make them useful in the digital world [12]. The company was incorporated on 29th December 1945, in Mumbai by Mohamed Premji as' Western India vegetable products limited 'later abbreviated to Wipro' [13]. A globally known company for its thorough business portfolio, a secure commitment to sustainability, and good corporate citizenship. There are 175,000 bound employees serving customers across six continents [12]. Bangalore-based Wipro Limited, India's third-largest company, Wipro 's chairman and managing director, Azim Hasham Premji, is committed to the diversified business model of the company, its future lies in its continuing achievement in software and IT services, which accounts for almost half of the organization's sales and has consistently outperformed the growth of other Wipro businesses [14].

\section{DIVERSITY AND INCLUSION AT WIPRO LTD :}

Wipro's Diversity \& Inclusion was officially launched in 2008. Nurturing inclusivity is an integral part of the organization, it has remained a core focus area for the company and is a strategic enabler for ensuring the universal growth of companies. customer portfolio at Wipro is diversified in size, in terms of regions, history, industries, and technologies. To take up the growing complexities of such a diverse clientele, it is imperative to develop a workforce that can produce a rich mosaic of ideas that enhance originality leading to bigger revenues and greater customer fulfilment [15]. The organization believes that it is not only important for Wipro's business to have a diverse workforce it is an important element as it promotes an inclusive culture that benefits every stakeholder. Wipro has commenced on a journey called 'winspire' to achieve the same, which places creativity as a base [16]. Wipro is bound to becoming an employer with equal opportunities and the ideals with diversity and inclusion are entrenched in companies' corporate values, philosophy, policies, and processes. The organization's dedication to non-discrimination and meritocracy is made fair in our COBC and Global Policy on Diversity \& Inclusion. Executive engagement, a committed society, and its involvement are essential to organize a vision that drives action. The president, Mr. Azim Premji as the main signatory and the D \& I Council being formed by the CEO, Executive Vice President Human Resources, and Legal Counsel. As Chairman of the Catalyst India Advisory Board and member of the Catalyst Global Board 
of Directors, CEO influences global stakeholders to promote gender equality in the broader society [17].

\section{BEST PRACTICES AT WIPRO :}

Wipro's diversity program is fabricated on four important pillars including gender, persons with disabilities, nationality, and underprivileged and disadvantaged communities (Figure 1).

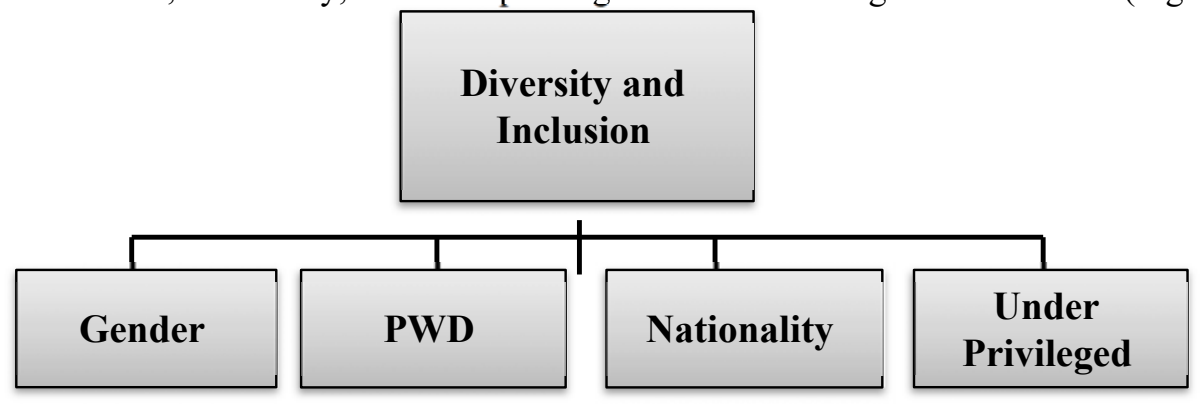

\subsection{Gender diversity:}

Fig. 1: Wipro's diversity program

One of India's leading information technology organizations, Company started gender inclusiveness approach with three core principles that drive women's needs in various life cycle cycles, such as exposure, flexibility, and empowerment. "Women of Wipro," popularly known as WOW led by senior management, groups of decisive action originally formed at each location and company unit. This program enables women executives from their company to channelize their passion for their personal and professional growth and provides the needed platform for their long-lasting career [18]. WOW has expanded a segmented approach to gender diversity that emphasizes on three major themes focusing on the employee's life-stage -Exposure (Life-stage I): Fuelling ambition by providing greater visibility. Flexibility (Life-stage II): Opportunity to grow by instituting flexible policies and processes Empowerment (Life-stage III): Making a difference by increasing access [19].

Stage 1: exposure (early career stage): The gender-sensitive organizational program aims at developing a more inclusive job forum and offering equal work opportunities for men and women. They have many projects, such as the WOW speaker series, where job rotations are carried out in an organized manner and networking is also provided.

Stage 2: flexibility (mid-career stage): The organization provides custom-made programs to help women balance they are work-life and also make sure their careers progress. To help this effort, maternity benefits and statutory minimum terms are extended and opportunities are given for re-entry after maternity breaks.

Stage 3: empowerment (advanced career stage): initiatives aims at advancing women in their career to make the work more Delightful. Such programs include direct mentoring with top management, succession planning, and identifying women in pipelines, leadership workshops, and career conversations [18].

Wipro has certain curriculum include exclusive workshops on diversity and inclusiveness, a special site for the initiative Women of Wipro, Kids@wipro including special initiatives for Wiproite children, mentoring, leadership sessions, WOW networking sessions and many others that help Wipro create an inclusive and welcoming environment in which women employees can continue their work. Wipro 's Corporate Diversity Council - a body comprising senior executives including the CEOs of Wipro 's various undertakings meet twice a quarter to provide feedback and regulate its inclusion and diversity initiatives [19].

\subsection{Persons with Disabilities (PwD) Program:}

Wipro's Persons with Disabilities (PwD) inclusion system target six chief policy areas, which include Attainable Infrastructure, Accessible Information Systems, Recruitment, Education, and Understanding. The relationship with the Diversity and Equal Opportunity Centre (DEOC) extended to educate on accessibility measures for disabled workers. This initiative was started in 2008[20]. Wipro employed all of its employees based merely on merit and it believes that individuals with disabilities should apply for each of these posts. The number of workers who revealed their disabilities 
has exceeded more than 440 in the last four years. The company has also looked at various areas of services, preparation, and sensitization to help the differently able citizens' [20].

\section{(1) Collaborations:}

Wipro is a member of the Indian Industry Confederation (CII), the Software and Services Companies National Association (NASSCOM), and the International Labor Organization (ILO). It has run job fairs with CII and NGOs such as Sarthak, Capacity Base, and Empower India to help people with different skills with a forum find work opportunities in addition to organizing inclusive campus hiring with JSS, Dr. Ambedkar Institute of Technology for Handicapped (AITH), and National Institute of Speech and Hearing (NISH). Wipro has established relationships with colleges where students with disabilities are present and people actively encourage in [21].

\section{(2) Barrier-Free Infrastructure:}

'Breaking all barriers' contest was held for employees to evaluate and suggest improvements to Wipro's physical infrastructure. Wipro's Building Codes (formerly based on the National Building Code 2005) have been amended to incorporate international guidelines developed by the United Nations 'Accessibility for the Disabled, A Barrier Free Space Development Manual' and the new draft Building Code drafted by the National Center for the Promotion of Employment for the Disabled (NCPEDP) and Accessibility, India. Such standards lay the basis for all new developments.

\section{(3) Barrier-free Communication:}

The portal 'Kinesics' provides a channel for employees across the globe to understand the techniques of sign language and apply it to terminology that is prevalent in the IT environment. It's been upgraded with a focus on making our information systems more accessible. The 'Inclusive' initiative was integrated with the organization's online enterprise social networking platform to enhance communication and interaction between employees. Inclusive is a vibrant community of employees with disabilities that discusses the IT-enabled applications' accessibility and provides suggestions and change requests. The Yammer page of Inclusive has 230 employees.

\section{(4) Engagement:}

Networking opportunities were provided to persons with disability connect at Global Forums - In 2015, A Wiproite was chosen among four others from India to represent at UN's; One youth representative with hearing impairment presented a paper in the Youth Program conducted by Disabled People's International (DPI) during the Conference of State Parties in the United Nations in New York in 2015. Exclusive 'Annual Global All Hands Meet' for People With Disability at Wipro was organized to provide a platform for leadership connect, networking interaction with Industry experts in the field of disability and to reward and recognize PWDs and their managers at Wipro who have excelled in their work and also supported Wipro in making it inclusive.

\section{(5) Advocacy:}

Wipro offered assistance to other independent bodies' disability initiatives \& Campaigns. For example, in partnership with the Ability Foundation, Wipro sponsored their Ability Fest 'A film streaming festival to raise awareness in the disability region,' Wipro coordinated a Deal Foundation Campus Connect for students with visual impairment. For a seminar on 'Sourcing non-conventional skills make business sense' by NHRD, Kolkata, Wipro participated in a guest session on insights from industry experts [20].

\subsection{Nationality:}

Employing people around the globe while serving global customers is an equally important aspect of Wipro's insight into becoming a truly global company. To develop sensitivity towards different cultures, the company has infused in advanced online tools like' Globe Smart' Besides, staff traveling overseas are expected to participate in an' Onsite Readiness Program' focused on a 2-day course, which includes a cultural sensitivity module. In addition to Onsite Readiness and Cross-culture Sensitivity schedules, specific culture sensitization sessions are held for all account team members. [22].

\subsection{Persons from Underprivileged Societies:}

The organization claims that constitute opportunities for people from underprivileged societies will not only broaden the pool of candidates but will also add a highly devoted workforce to the organization. The key strategies to increase the niche.

$>$ Collaborate with colleges/universities in small cities to propel recruitments. 
> Collaborate with NGOs/Foundations which convey skills training to graduates from underprivileged societies.

$>$ Collaborate with state governments in areas like the north-east to impart expertise and training to trainers [23].

8. REPORTS OF DIVERSITY AND INCLUSION OF WIPRO CO LTD. AS PER THE SUSTAINABILITY REPORTS OF 3YEARS [24], [25], [26]:

Table 3: Diversity and inclusion report of Wipro ltd

\begin{tabular}{|l|c|}
\hline Years & Reports \\
\hline $2019-2018$ & $>$ inclusive gender diversity is 35.2 percent $(0.2$ percent higher YoY) \\
& $>16.9$ percent of women in management positions (both middle and senior \\
& $>$ executives) \\
& $>$ About 125 nationalities \\
& $>545$ disabled employees (with 15 types of disability). \\
& $>35 \%$ of gender diversity (2\% higher YoY) \\
& $>16 \%$ Women in management roles (in junior, middle, and senior managers) \\
& $>110$ nationalities \\
& $>65 \%$ of the onsite staffs are locals \\
& $>442$ employees with disabilities, employed (with 8 different types of \\
& $>33 \%$ Women workforce \\
& $>100+$ nationalities from $50+$ countries, $42 \%+$ of employees outside India are \\
& $>10$ locals \\
& $>334$ employees with disabilities \\
&
\end{tabular}

\section{MEASURES TO IMPROVE INSIGHT AND UNDERSTANDING OF DIVERSITY IN THE} WORKPLACE [27] :

1. By eliminating biases and using stereotypes

* Acknowledging that diversity exists and learning to accept and appreciate fundamental differences

* Accepting and committing to that one's own biases and prejudices

* Suppressing misconceptions about different others while in a community of friends or associates

2. By raising miscommunication with various others

* Educating one's identity about differences by reading, listening and extending one's knowledge base on different people

* constantly communicating by listening carefully and asking questions about what one did not understand

* Avoiding words that illustrate other groups and suggest individuals is an exception

- Avoiding acceptance of one's message based on appearance, mannerisms, accent, or eye contact.

3. Fostering relationships with diverse others.

* a gradual increase in constructive relationships with diverse others

* Receiving input from diverse others on how well one expresses respect for them and appreciates their diversity

* Treating diverse others as special guests by expressing interest in them rather than treating them as strangers

10. ABCD ANALYSIS ON DIVERSITY AND INCLUSION OF WIPRO COMPANY LTD : 
The ABCD approach can be used to examine the value of the company in the society on the following grounds:

- Individual characteristics,

- Framework characteristics,

- Concept or idea effectiveness,

- Strategy effectiveness

The framework for ABCD analysis can be used for any form of Case Study of an organization. This analytical methodology is simple and straightforward and can be used to evaluate several company issues or problems to find a suitable solution through simplifying the problems by determining the factors that affect them through factor analysis and critical elements through intermediate analysis [2830]

Table 4: The table showing ABCD analysis of diversity and inclusion of Wipro company ltd.

\begin{tabular}{|l|l|}
\hline Advantage & - Inumerable opportunities \\
& - Pool of talents \\
& - Economic development \\
& - Enhanced creativity \\
\hline Benefits & - Impreased turnover \\
\hline & - Improv organizational culture \\
& - Improved business performance \\
& - Benefits to the shareholders \\
\hline Constraints & - High cost \\
& - Increased conflicts/grievances \\
& - Technological errors \\
& - Disruption of work \\
\hline Disadvantages & - Communication issues \\
& - Discrimination \\
& - Conflicts/grievances \\
& - Stereotypes \\
\hline
\end{tabular}

\section{FINDINGS :}

1. Wipro Lt has a huge spectrum of diversity and inclusion practices that enable employees to strengthen productivity and performance.

2. Initiatives of gender diversity implemented by Wipro ltd under the WOW program have been successful for women workers

3. PWD Diversity Dimension has concentrated on six areas where the organization hires and prepares and empowers PWD employees so that they can work efficiently without complications.

4. The aspect of nationality made it feasible for Wipro employees worldwide to become virtual worldwide.

5. Recruiting underprivileged workers would improve the organization's top talent and intenselycommitted staff.

\section{CONCLUSION :}

Organizations in the modern world will have to face stringent competition in all areas of business. Its survival and sustenance will depend to a very large extent on how it adapts to the modern approaches to business. Foremost among them are organizational diversity and inclusion. Diverse perspectives help create new solutions to help overcome several barriers. Organizations need to build long-term goals and strategies to leverage the energy that diversity and inclusion bring to the workplace. A long- 
term strategy respects differences and supports them for motivating workers to think freely. By embedding diversity and inclusion as an asset, businesses can better prepare themselves for the future.

\section{REFERENCES :}

[1] Rao, S. R., \& Bagali, M. M. (2014). Workforce Diversity and Management: An Empirical Study on Relationship between Diversity Management Practices, Obstacles, and Acceptance of Gender Diversity among Employees in IT Industry; Bangalore. Journal of Business and Management, 16(2), $12-25$.

[2] Otike, W., Messah, B., \& Mwaleka, K. (2010). Effects of Workforce Diversity on Organizational Effectiveness: A Case Study On Kenya Commercial Bank Ltd. Journal Of Business And Management, http://citeseerx.ist.psu.edu/viewdoc/download?doi=10.1.1.1008.9951\&rep=rep1\&type=pdf.

[3] https://au.gradconnection.com/employers/wipro/inclusion-and-diversity/] retrieved on 7.05.2020.

[4] Dixit, P., \& Bajpai, B. L. (2015). Managing workforce diversity in a competitive environment. International Journal of Business and Management Invention (IJBMI), 4(1), 1-11.

[5] Niyaz (2014). HRM and Diversity Management: A Case Study on Managing Diversity in Multinational Company Special Reference Infosys Limited, Global Research Analysis, 3(4), 128-133.

[6] Gupta, R. (2011). Workforce Diversity and Organizational performance. International Journal of Business and Management Invention, 2(6), 36-41.

[7] Itam, U., \& Bagali, M. M. (2019). Diversity and Inclusion Management: A Focus on Employee Engagement. In Gender and Diversity: Concepts, Methodologies, Tools, and Applications (pp. 17711788). IGI Global.

[8] Deshpande, A. (2014). A comparative study of workforce diversity in the service and manufacturing sectors in India. IMPACT: International Journal of Research in Business Management, 2 (3), 1-8.

[9] Singh, S., Ganguli, S., \& David, R. (2017). Women Workforce Attrition Dynamics in Indian IT/ITES Sector. Qualitative Report, 22(5), 1211-1226.

[10] Roberge, M. É., \& Van Dick, R. (2010). Recognizing the benefits of diversity: When and how does diversity increase group performance?. Human Resource management Review, 20(4), 295-308.

[11] Solanki, R. B., \& Saxena, A. (2016). Workforce diversity and its impact on productivity. Prestige International Journal of Management and Research, 10(1), 33-48.

[12] www.wipro.com retrieved on 9.05.2020.

[13] www.slideshare.comretrieved on 09.05.2020.

[14] https://www.referenceforbusiness.com/history2/73/Wipro-Limited.htmlretrieved on 20.05.2020

[15] http://wiprosustainabilityreport.com/16-17/diversity and inclusion retrieved on 19.05.2020

[16] http://wiprosustainabilityreport.com/16-17/diversity_and_inclusion retrieved on 19.05.2020.

[17 http://wiprosustainabilityreport.com/15-16/?q=diversity-inclusion retrieved on 16.05.2020.

[18] https://www.scribd.com/document/358767235/Wipro-Women-Initatives-pdf retrieved on $\underline{19.05 .2020}$

[19] http://cbsmohali.org/img/WIPRO\%20Ltd.pdf retrieved on 28.04.2020

[20] http://wiprosustainabilityreport.com /15-16/?q=persons-disabilities-pwd-program retrieved on 28.04.2020.

[21] Vohra, N., Chari, V., Mathur, P., Sudarshan, P., Verma, N., Mathur, N.,\& Dasmahapatra, V. (2015). Inclusive workplaces: Lessons from theory and practice. Vikalpa, 40(3), 324-362.

[22] http://wiprosustainabilityreport.com/14-15/?q=nationalityretrieved on 19.05.2020 
[23] http://wiprosustainabilityreport.com/ 14-15/?q=persons-underprivileged-societies retrieved on 19.05.2020.

[24] https://www.wipro.com/ content/dam/nexus/en/investor/annual-reports/2018-2019/annual-reportfor-fy-2018-19.pdfretrieved on 26.01.2020.

[25] https://www.wipro.com/content/ dam/nexus/en/sustainability/sustainability_reports/ sustainability-report-fy-2017-18.pdf. retrieved on 19.05.2020.

[26] http://wiprosustainabilityreport.com/16-17/diversity and inclusion retrieved on 19.05.2020.

[27] Bedi, P., Lakra, P., \& Gupta, E. (2014). Workforce diversity management: Biggest challenge or opportunity for 21st-century organizations. Journal of Business and Management, 16(4), 102-107.

[28] Aithal, P. S. (2017). Industry Analysis-The First Step in Business Management Scholarly Research. International Journal of Case Studies in Business, IT, and Education (IJCSBE), 1(1), 1-13.

[29] Aithal, P. S. (2017). ABCD Analysis as Research Methodology in Company Case Studies. International Journal of Management, Technology, and Social Sciences (IJMTS), 2(2), 40-54.

[30] Aithal, P. S. (2017). Company Analysis-The Beginning Step for Scholarly Research. International Journal of Case Studies in Business, IT, and Education (IJCSBE), 1(1), 1-18. 